\title{
Availability and Equality of Health Services: The Reduction of the Influence of Social Class on Obstetric Health Behavior in Northern Bangladesh
}

\author{
Md. Bokul Hossain', Md. Siddiqur Rahman² \\ ${ }^{1}$ Department of Sociology, First Capital University of Bangladesh, Chuadanga, Bangladesh \\ ${ }^{2}$ Department of Sociology, University of Rajshahi, Rajshahi, Bangladesh \\ Email: bokulhossain2625@gmail.com,sr_soc@yahoo.com
}

How to cite this paper: Hossain, Md.B. and Rahman, Md.S. (2019) Availability and Equality of Health Services: The Reduction of the Influence of Social Class on Obstetric Health Behavior in Northern Bangladesh. Health, 11, 1186-1205.

https://doi.org/10.4236/health.2019.119093

Received: August 18, 2019

Accepted: September 26, 2019

Published: September 29, 2019

Copyright ( 2019 by author(s) and Scientific Research Publishing Inc. This work is licensed under the Creative Commons Attribution International License (CC BY 4.0).

http://creativecommons.org/licenses/by/4.0/

(c) (i) Open Access

\begin{abstract}
The present study attempts to examine the influence of social class (in terms of educational qualification, the occupation of the husband and monthly family income of the respondents) on obstetric health behavior (in terms of antenatal care or ANC visits, the intake of iron tablets, tetanus toxoid vaccination of mother, types of birth attendant, sources of information about obstetric health) in some suburban places of northern Bangladesh. Mix methods have been executed to conduct the present study. A total of one hundred and twenty-five (125) women who gave birth within the last two years have been selected through purposive sampling. Besides ten (10) case studies and five (5) key informants analysis have been performed in this study. As all the variables; both dependent and independent; used in this study are categorical, the Chi-square test has been used to assess the relationship between social class and obstetric health behavior. In this study, a significant association has been found between taking of iron tablets and occupation of the husband $(\mathrm{P}=$ 0.026); taking of iron tablets and educational qualification $(P=0.029)$; vaccination of mother (TT) and educational qualification $(\mathrm{P}=0.004)$, whereas the association of other variables regarding social class and obstetric health behavior has been found insignificant. So the present study shows that the influence of social class on obstetric health behavior has been significantly reduced. It is evidenced that nowadays the effect of social class on obstetric health behavior has significantly faded by the availability, equality-based health services, and services through satellite clinics in the study area. Stakeholders and concerned authorities should give top priority to the findings while developing strategies to improve the condition of maternal health of
\end{abstract}


Bangladesh to acquire the aims of reducing maternal mortality to less than 70 deaths per 100,000 live births.

\section{Keywords}

Social Class, Obstetric Health, Obstetric Health Behavior (OHB), Suburban

\section{Introduction}

Health is a holistic concept [1]. According to the World Health Organization, "Health is a state of complete physical, mental and social well-being and not merely an absence of disease or infirmity" [2]. In the discussion of health, obstetric health behavior is very important. Because it is related to maternal mortality ratio (MMR) which is now widely considered as a crucial indicator of the overall health status of a country. Over the last two decades of the past century, women's health issues have attained higher international visibility and renewed political commitments [3].

The international community has repeatedly declared its commitment to reduce the high levels of maternal mortality in developing countries, starting with the 1987 Safe Motherhood Conference in Nairobi, Kenya, followed by the 1990 World Summit for Children at United Nations Headquarters, the 1994 International Conference on Population and Development in Cairo, Egypt, the 1995 Fourth World Conference on Women in Beijing, China, "Nairobi 10 Years On" in Sri Lanka in 1997, the Millennium Development Goals in 2000 [4].

And at last The Sustainable Development Goals established by the United Nations in 2015 has also emphasized on it. Many initiatives have been taken through these conferences throughout the world. These initiatives have been trying to enable women to live a healthy life through different policies and programs. But, socio-cultural factors have influenced women's health, especially obstetric health in different ways. Among the factors, social class has been taken into consideration in this study. A number of studies on factors influencing obstetric health care have been reviewed, and they have shown that factors like education, place of residence, occupation, maternal age, number of living children, gravid, marital status, religion, and ethnicity are significantly associated with the use of antenatal care. Besides, these studies have been conducted in either rural or urban settings [5]-[16]. Generally, three kinds of research gaps are found through literature reviews like data or contextual gap, methodological gap and theoretical gap. The present study is conducted on the basis of data or contextual gap and theoretical gap. So, the present study has been conducted to assess the influence of social class on obstetric health behavior in terms of the monthly income of the respondents' family, the educational qualification of the respondents, and the occupation of the husband of the respondents using some suburban places of northern Bangladesh. The findings will be helpful in policy 
making to acquire the third goal of Sustainable Development Goals (SDGs).

\section{Objectives of the Study}

The general objective of the present study attempts to examine the influence of social class on obstetric health behavior in some suburban places of northern Bangladesh. More specifically, the researcher examines the influence of the educational qualification of the respondents, the occupation of the husband, and monthly family income of the respondents on the rate of receiving ANC visits, the intake of iron tablets, vaccination of mother (TT), types of birth attendant and sources of information regarding obstetric health.

\section{Overview of the Problem}

Many women die and suffer from various preventable complications every year all over the world.

According to WHO factsheets, every day, approximately 830 (302,950 in a year) women die from preventable causes related to pregnancy and childbirth and $99 \%$ of all maternal deaths occur in developing countries. Maternal mortality is higher in women living in rural areas and among poorer communities. Young adolescents face a higher risk of complications and death as a result of pregnancy than other women. Skilled care, before, during and after childbirth, can save the lives of women and newborn babies. Between 1990 and 2015, maternal mortality worldwide dropped by about 44\%. Between 2016 and 2030, as part of the Sustainable Development Goals, the target is to reduce the global maternal mortality ratio to less than 70 per 100,000 live births. The high number of maternal deaths in some areas of the world reflects inequities in access to health services and highlights the gap between rich and poor. Almost all maternal deaths (99\%) occur in developing countries. More than half of these deaths occur in sub-Saharan Africa and almost one third occur in South Asia. More than half of maternal deaths occur in fragile and humanitarian settings. The maternal mortality ratio in developing countries in 2015 is 239 per 100,000 live births versus 12 per 100,000 live births in developed countries [17].

Bangladesh is a developing south Asian country which has achieved great success in several fields. Since the country's independence in 1971, the government of Bangladesh has been making a great effort to provide health and family planning services in the whole area of the country [18]. According to the Bangladesh Ministry of Health and Family Welfare, maternal mortality ratio of Bangladesh is 176 per 100,000 live births (in 2015; World Bank, 2016) and 196 per 100,000 live births (Bangladesh Maternal Mortality Survey, 2016) [19]. Besides, Maternal Mortality Ratio has declined significantly: from 322 to 194 maternal deaths per 100,000 live births between Bangladesh Maternal Mortality Survey 2001 and Bangladesh Maternal Mortality Survey 2016. This is remarkable progress for Bangladesh which is linked to socioeconomic improvements; fertility reduction; increased access to maternal health care; increased use of maternal 
health services in the antenatal, delivery, and postpartum periods.

Although different reports show that some visible progress has occurred in maternal health condition in the past two decades, obstetric complications are still a major cause of death among women in developing countries like Bangladesh. According to the World Health Organization, while motherhood is often a positive and fulfilling experience, for too many women it is associated with suffering, ill-health, and even death. The major direct causes of maternal morbidity and mortality include hemorrhage, infection, high blood pressure, unsafe abortion and obstructed laborer [20]. These obstetric complications are highly related to obstetric health behavior like antenatal care (ANC) visit, the intake of iron tablets, tetanus toxoid (TT) vaccination of mother, place of delivery, types of birth attendants, and sources of information regarding obstetric health. Besides, obstetric health behaviors are related to many socio-cultural factors. Social class is the most important of them all. In this circumstance, we ought to know about the impact of social class on obstetric health behavior to acquire the goal-3 of Sustainable Development Goals (SDG). The relationship between social class and obstetric health behavior is factorial in nature.

\section{Operational Definition of Key Concepts}

The following concepts below are defined with a view to clarifying the connotation in which they are used in the present study:

\subsection{Obstetric Health}

In this research obstetric health refers to the health of women during pregnancy, childbirth and postnatal period.

\subsection{Obstetric Health Behavior}

Obstetric health behavior is the sum total of action that is taken by a woman, her family as well as society to maintain, attain, or regain good health and to prevent illness during the period of pregnancy, childbirth and postpartum. In this study ANC visit, the taking of iron tablets, vaccination of mother (TT), types of birth attendant, sources of information about obstetric health are considered as obstetric health behavior.

\subsection{Social Class}

In this study, social class is defined in terms of educational attainment, the income level of the respondent's family and occupation of the husband of the respondents.

\subsection{Suburban}

In this study, the term suburban is used in lieu of suburb which is defined as an area on the edge of a large town where people who work in the town or city often live. A suburb is a mixed-use or residential area, existing either as part of a 
city or urban area or as a separate residential community within commuting distance of a city. Suburbs tend to proliferate around cities that have an abundance of adjacent flat land.

\section{Theoretical Framework}

The present research is related to Medical Sociology. A good number of theoretical propositions are available in the field of Sociology. But almost all theories of sociology are developed in the context of developed countries. For this reason, a particular theory cannot explain a fact completely in the context of a developing country. It takes more than one theory to explain the fact of a developing country. In Bangladesh, it seems to gain more complexities, controversies, and confusion. Anyway, "Health Care Utilization Model" by Andersen has been taken as a guided model in this study [21]. Health Care Utilization Model is a determinants model which is based on a more bio-medical and quantitative approach [22]. This model specifically focuses on one's health behavior and helps us to understand how and why one would seek care earlier than others. The determinants model of Andersen consists of three principal components. The components are 1) predisposing factors (i.e. Demographic Factors: age, sex, marital status. Social Structure: education, occupation, family size, religion. Health Belief: attitude, values, and knowledge about health services.); 2) enabling factors (Family Resources: economic status, location of residence and quality of social relations. Community Resources: available health services, health organization, health policy, social network.); 3) need factors (Perceived Need: respondents, husband, household head and other members. Evaluated Need: Health worker and service providers). Besides, "Marxist Theory of Social Class" has been taken as a guided theory in this study. According to Haralambos, Holdborn, and Heald, the concept of health varies according to a social group. Since wealth or socio-economic factor determines the health status of both the individual and society it becomes obvious that the poor health of women especially those that live in rural areas are as a result of the poor economic condition [23]. However, Marxian theories generally have been subjected to a number of criticisms.

\section{Methodology}

The present research is explanatory in nature and executes both qualitative and quantitative methodology. Purposive sampling survey, case study and key informant analysis have been used as methods in the present study. For the collection of data a structured questionnaire was designed first in the English language on the basis of literature review of previous studies on women's perceptions of maternal health issues, social and cultural barriers of maternity care, and factors affecting obstetric healthcare, comprised of different sections such as personal and family information of the respondents, socio-economic data of the respondents, knowledge of women about antenatal care, social class and obstetric health behavior. This includes knowledge about signs and symptoms of pregnancy, diet in pregnancy, preventing anemia, danger signs in pregnancy and re- 
lationship between social class and obstetric health behavior. Both open-ended and close-ended questions have been included. The questionnaire was translated to Bangla and then translated back to English to identify any change in meaning or phrasing. Pre-testing has been conducted in another similar setting. For pre-testing, questionnaires have been administered to ten percent of the total sample size. The questionnaire has been revised after pre-testing and necessary amendments have been made. Besides data have been collected through Bangla language which is the native language of the people of the study area and seven female students have given assistance in this regard. Moreover, checklist, tape recorder, and mobile phone have been executed as tools of data collection. Depending on the nature of the present study interview, in-depth interview and empirical observation have been used as the techniques of data collection. Data has been collected mainly from the primary source. A secondary source has also been applied to strengthen primary data. The researcher has purposefully chosen 30 no. ward of Rajshahi City Corporation as a study area. This ward consists of seven colonies named Budpara, Mohonpur, Mirzapur, Choddopai, Maskata Digi, Behas and Rajshahi University. For identifying the population of the given area, a baseline survey was conducted and it had been found that the total number of households is around 2700 and the number of women who have delivered within the last two years is 1212. In 2016 it was 613 and in 2017 it was 599 (Raw data from Expanded Program on Immunization of Rajshahi City Corporation). It is censured by the local govt. and the community health center situated in the study locale. Among those 1212 women who have delivered within the last two years, 125 have been selected as sample by using the sample size calculator of Australian Bureau of Statistics (ABS) which is $10 \%$ of the total population (Confidence Level $=95 \%$, Population Size $=1212$, Proportion $=0.1$, Confidence Interval $=0.05$, Confidence Interval: Upper $=0.15000$ and Lower $=0.05000$, Standard Error $=0.02551$, Relative Standard Error $($ RSE $)=25.51$, Sample Size $=125)$. Both individual and household have been considered as the unit of analysis of this research. Besides, ten (10) case studies and five (5) key informant analyses have been performed in this study. The present research has been carried out for a period of three months and data were collected for a period of 29 days from 23 January 2018 to 20 February 2018. In the present study, the researcher has used various statistical methods such as tabulation, classification, frequency distribution, percentage, different measurement scales like Chi-Square Tests for processing and analyzing primary data. Besides two computer software like Microsoft Office Excel-2007 and Statistical Packages for the Social Sciences (SPSS)-20 have been used for the interpretation and presentation of obtained data.

\section{Results}

\subsection{Socio-Demographic Status}

Age is a very important demographic variable. Besides, the social perception of age is also very important in the regard. Many important things in human life 
depend on age and social conception. Obstetric complications are the most familiar of these. So in this study, I consider the respondent's age as a crucial element. It is seen from the given table (Table 1) that the age of most of the respondents (92\%) of this study are between 15 and 30 years. Only $8 \%$ of them are above 30 years. This age structure provides a brief conception of reproductive age of the research area, as well as Banglades as a whole which is very relevant to this study.

Obstetric health behavior mostly depends on the family structure. It is known from the key informant analysis that in most nuclear families the family decision is made by the husband and women have some access to influence upon it. On the other hand, decisions in an extended family come from the father, or from the father-in-law. In this situation, women, especially, the daughters-in-law face various problems, because they cannot share all things with their father-in-law whereas they share all things regarding obstetric health with their husband freely. Obstetric health behavior of a family is highly influenced by these situations. The present research reveals that $59.2 \%$ of the respondents belong to nuclear family and $40.8 \%$ belong to extended family (Figure 1). Everything has both positive and negative side. Extended family structure has some positive side also. Especially, during postpartum period it brings some positive consequence for baby and mother whereas nuclear families fail to maintain such things.

Here, problems during pregnancy mean the five danger signs like vaginal bleeding, convulsion or fits, severe headaches with blurred vision, fever and weakness, and severe abdominal pain. Besides, many of them face other complications like anemia, edema, high BP, severe vomiting and distaste for food. The present research shows that the 64 respondents did not face these problems during pregnancy, which is $51.2 \%$ of the total respondents. Whereas, the 61 respondents faced at least one of the problems mentioned above during pregnancy, which is $48.8 \%$ of the total respondents (Figure 2). Besides, they faced other problems like vomiting, distaste in food, etc. On the other hand, most of them who have faced problems during pregnancy have consulted a doctor. The table shows that among them $95.08 \%$ visited a doctor whereas $4.92 \%$ did not visit a doctor in this regard (Table 2).

Table 1. Distribution of the age of the respondents.

\begin{tabular}{cccc}
\hline Age (years) & Frequency (f) & Percent (\%) & Cumulative percent \\
\hline $15-20$ & 39 & 31.2 & 31.2 \\
$21-25$ & 44 & 35.2 & 66.4 \\
$26-30$ & 32 & 25.6 & 92.0 \\
$31-35$ & 6 & 4.8 & 96.8 \\
$36-40$ & 4 & 3.2 & 100.0 \\
Total & 125 & 100.0 & \\
\hline
\end{tabular}


Table 2. Receiving of doctor's consultation during pregnancy.

\begin{tabular}{lcc}
\hline Receiving of doctor's consultation & Frequency (f) & Percent (\%) \\
\hline Yes & 58 & 95.08 \\
No & 3 & 4.92 \\
Total & 61 & 100.0 \\
\hline & & \\
& & \\
& &
\end{tabular}

Figure 1. Types of family structure.

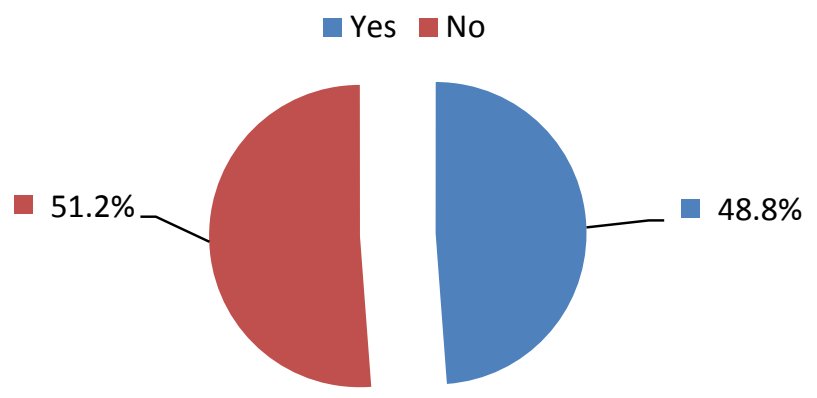

Figure 2. Problems during pregnancy.

The present research shows that the complications grew in only $32 \%$ deliveries, whereas $68 \%$ of respondents delivered without any complications (Figure 3). Here delivery complications include many problems like convulsions, prolonged labor, severe bleeding, high blood pressure (BP.), leaking membrane, obstructed labor, retained placenta, etc. On the other hand, almost all respondents (97.5\%) who have faced complications during delivery have taken doctor's consultation. Only $2.5 \%$ did not take consultation. Poverty is the main cause of it (Table 3).

Place of delivery is a vital indicator of understanding obstetric health behavior. The ratio of hospital delivery of a given area portrays the whole condition of the health system. Because it presents both health care delivery system and people's attitude regarding health simultaneously. The present research shows that $93.6 \%$ deliveries were held in the hospital and only $6.4 \%$ of women gave delivered their children at home (Figure 4). Besides, they (6.4\%) got assistance from Traditional Birth Attendant (TBA).

The table shows that the respondents who gave birth at the hospital got assistance from skilled birth attendant (SBA) which is $93.6 \%$ and only $6.4 \%$ women who gave delivery at home got assistance from Traditional Birth Attendant (Table 4). 


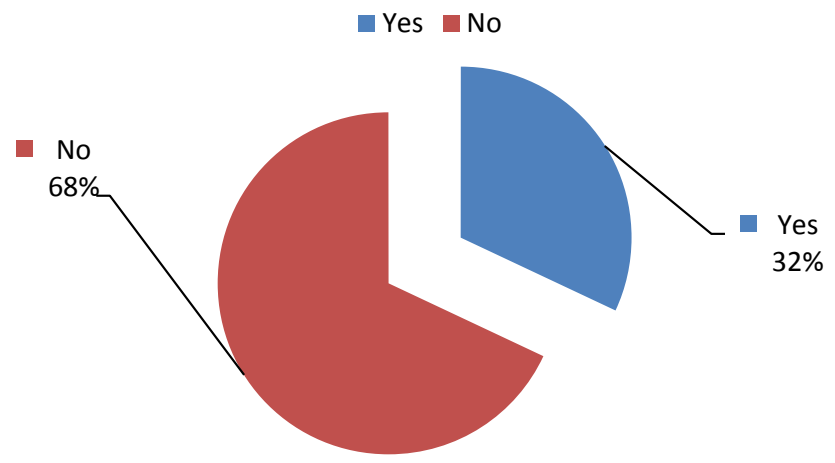

Figure 3. Problems during delivery.

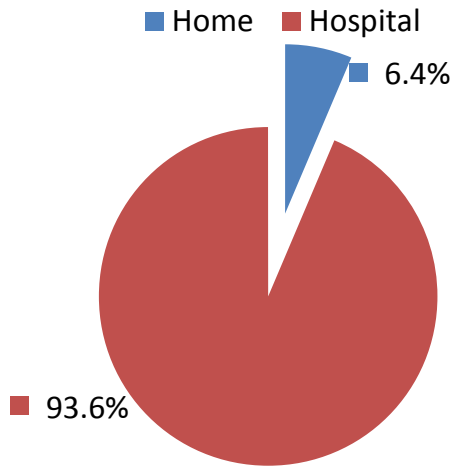

Figure 4. Place of delivery.

Table 3. Receiving of doctor's consultation during delivery.

\begin{tabular}{ccc}
\hline $\begin{array}{c}\text { Receiving of doctor's } \\
\text { consultation during delivery }\end{array}$ & Frequency (f) & Percent (\%) \\
\hline Yes & 39 & 97.5 \\
No & 1 & 2.5 \\
Total & 40 & 100.0 \\
\hline
\end{tabular}

Table 4. Types of births attendants.

\begin{tabular}{ccc}
\hline Types of births attendants & Frequency (f) & Percent (\%) \\
\hline TBA & 8 & 6.4 \\
SBA & 117 & 93.6 \\
Total & 125 & 100.0 \\
\hline
\end{tabular}

TBA = Traditional Birth Attendant; SBA = Skilled Birth Attendant.

In Bangladesh,births attended by skilled health personnel (\%): 42.1 (BDHS, 2014) C-section rate (\%): 22.9\% (BDHS, 2014) Home delivery rate: $62.2 \%$ (BDHS, 2014) (Bangladesh Ministry of Health and Family Welfare, 2017) [19].

The present study shows that most of the respondents (79.2\%) do not face any problem during postpartum and $20.8 \%$ of respondents face problems like anemia, abdominal pain, strong aversion, and etcetera (Figure 5). 


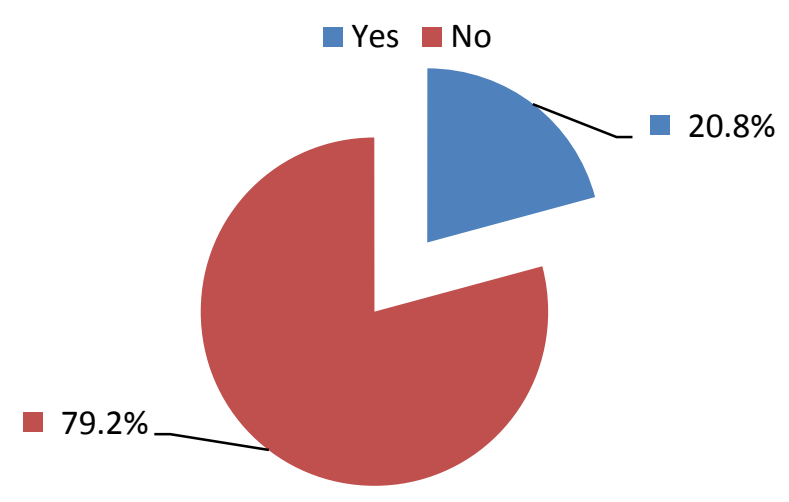

Figure 5. Problems during postpartum.

\subsection{The Influence of Social Class on Obstetric Health Behavior}

The relationship between social class and obstetric health behavior have been explained in terms of the relationship between the determinants of social class like educational attainment, monthly income level of the respondent's family, occupation of husband of the respondents and the determinants of obstetric health behavior like ANC visit, vaccination of mother (TT), the intake of iron tablets, types of birth attendant, and source of information regarding obstetric health. The influence of social class on obstetric health behavior is explained below:

The table (Table 5) shows the relationship between social class and ANC visits. In doing so, the researcher examines the association between monthly family income, occupation of husband, educational qualification of the respondents and ANC visits of the respondents by using Chi-squire test. The result shows that the association of the aforementioned variables is insignificant at 0.05 level of significance.

The table (Table 6) shows the relationship between social class and the intake of iron tablets as obstetric health behavior. The result shows that the association between the monthly family income of the respondent family and taking of iron tablets is insignificant whereas the association between the occupation of husband, educational qualification of respondent and taking of iron tablets has been found significant.

The table (Table 7) shows the relationship between social class and the vaccination of the mother (TT). It is observed from the result that the association between the monthly family income of the respondents, occupation of husband and TT vaccination of mother has been found insignificant whereas the association between educational qualification and TT vaccination of mother has been found significant.

The table (Table 8) shows the relationship between social class and types of birth attendants during delivery of the respondents. The association between the variables has been found insignificant.

The present table (Table 9) shows the relationship between social class and sources of information regarding obstetric health. The association between the 
Table 5. Social class and ANC visits.

\begin{tabular}{|c|c|c|c|c|c|c|c|c|c|}
\hline & & \multicolumn{6}{|c|}{ ANC visits } & \multirow{2}{*}{ Total } & \multirow{2}{*}{$P$-value } \\
\hline & & 0 visit & $1-3$ visits & 4 visits & 5 - 8 visits & $9-12$ visits & Above 12 & & \\
\hline \multirow{10}{*}{$\begin{array}{l}\text { Monthly income of } \\
\text { the respondents } \\
\text { family }\end{array}$} & \multirow{2}{*}{$<10,000$ (Taka) } & 1 & 3 & 0 & 10 & 10 & 4 & 28 & \multirow{10}{*}{0.616} \\
\hline & & $3.6 \%$ & $10.7 \%$ & $0.0 \%$ & $35.7 \%$ & $35.7 \%$ & $14.3 \%$ & $100.0 \%$ & \\
\hline & \multirow{2}{*}{$10,000-20,000$ (Taka) } & 0 & 10 & 6 & 19 & 29 & 4 & 68 & \\
\hline & & $0.0 \%$ & $14.7 \%$ & $8.8 \%$ & $27.9 \%$ & $42.6 \%$ & $5.9 \%$ & $100.0 \%$ & \\
\hline & \multirow{2}{*}{ 20,001 - 30,000 (Taka) } & 0 & 0 & 1 & 6 & 9 & 1 & 17 & \\
\hline & & $0.0 \%$ & $0.0 \%$ & $5.9 \%$ & $35.3 \%$ & $52.9 \%$ & $5.9 \%$ & $100.0 \%$ & \\
\hline & \multirow{2}{*}{$>30,000$ (Taka) } & 0 & 1 & 1 & 4 & 4 & 2 & 12 & \\
\hline & & $0.0 \%$ & $8.3 \%$ & $8.3 \%$ & $33.3 \%$ & $33.3 \%$ & $16.7 \%$ & $100.0 \%$ & \\
\hline & \multirow{2}{*}{ Total } & 1 & 14 & 8 & 39 & 52 & 11 & 125 & \\
\hline & & $0.8 \%$ & $11.2 \%$ & $6.4 \%$ & $31.2 \%$ & $41.6 \%$ & $8.8 \%$ & $100.0 \%$ & \\
\hline \multirow{12}{*}{$\begin{array}{l}\text { Occupation of } \\
\text { husband }\end{array}$} & \multirow{2}{*}{ Agriculture } & 0 & 1 & 0 & 1 & 1 & 0 & 3 & \multirow{12}{*}{0.739} \\
\hline & & $0.0 \%$ & $33.3 \%$ & $0.0 \%$ & $33.3 \%$ & $33.3 \%$ & $0.0 \%$ & $100.0 \%$ & \\
\hline & \multirow{2}{*}{ Business } & 0 & 5 & 2 & 18 & 18 & 1 & 44 & \\
\hline & & $0.0 \%$ & $11.4 \%$ & $4.5 \%$ & $40.9 \%$ & $40.9 \%$ & $2.3 \%$ & $100.0 \%$ & \\
\hline & Samice & 0 & 2 & 3 & 9 & 12 & 5 & 31 & \\
\hline & 年 & $0.0 \%$ & $6.5 \%$ & $9.7 \%$ & $29.0 \%$ & $38.7 \%$ & $16.1 \%$ & $100.0 \%$ & \\
\hline & \multirow{2}{*}{ Day labor } & 1 & 6 & 2 & 9 & 19 & 5 & 42 & \\
\hline & & $2.4 \%$ & $14.3 \%$ & $4.8 \%$ & $21.4 \%$ & $45.2 \%$ & $11.9 \%$ & $100.0 \%$ & \\
\hline & \multirow{2}{*}{ Others } & 0 & 0 & 1 & 2 & 2 & 0 & 5 & \\
\hline & & $0.0 \%$ & $0.0 \%$ & $20.0 \%$ & $40.0 \%$ & $40.0 \%$ & $0.0 \%$ & $100.0 \%$ & \\
\hline & \multirow{2}{*}{ Total } & 1 & 14 & 8 & 39 & 52 & 11 & 125 & \\
\hline & & $0.8 \%$ & $11.2 \%$ & $6.4 \%$ & $31.2 \%$ & $41.6 \%$ & $8.8 \%$ & $100.0 \%$ & \\
\hline \multirow{16}{*}{$\begin{array}{l}\text { Educational } \\
\text { qualification }\end{array}$} & \multirow{2}{*}{ Illiterate } & 0 & 1 & 0 & 1 & 0 & 0 & 2 & \multirow{16}{*}{0.513} \\
\hline & & $0.0 \%$ & $50.0 \%$ & $0.0 \%$ & $50.0 \%$ & $0.0 \%$ & $0.0 \%$ & $100.0 \%$ & \\
\hline & \multirow{2}{*}{ PSC } & 1 & 1 & 3 & 6 & 9 & 1 & 21 & \\
\hline & & $4.8 \%$ & $4.8 \%$ & $14.3 \%$ & $28.6 \%$ & $42.9 \%$ & $4.8 \%$ & $100.0 \%$ & \\
\hline & \multirow{2}{*}{ JSC } & 0 & 3 & 1 & 5 & 4 & 1 & 14 & \\
\hline & & $0.0 \%$ & $21.4 \%$ & $7.1 \%$ & $35.7 \%$ & $28.6 \%$ & $7.1 \%$ & $100.0 \%$ & \\
\hline & \multirow{2}{*}{ SSC } & 0 & 5 & 2 & 14 & 26 & 5 & 52 & \\
\hline & & $0.0 \%$ & $9.6 \%$ & $3.8 \%$ & $26.9 \%$ & $50.0 \%$ & $9.6 \%$ & $100.0 \%$ & \\
\hline & \multirow{2}{*}{ HSC } & 0 & 4 & 1 & 10 & 4 & 1 & 20 & \\
\hline & & $0.0 \%$ & $20.0 \%$ & $5.0 \%$ & $50.0 \%$ & $20.0 \%$ & $5.0 \%$ & $100.0 \%$ & \\
\hline & $C$ md not & 0 & 0 & 1 & 1 & 5 & 2 & 9 & \\
\hline & Miantuate & $0.0 \%$ & $0.0 \%$ & $11.1 \%$ & $11.1 \%$ & $55.6 \%$ & $22.2 \%$ & $100.0 \%$ & \\
\hline & & 0 & 0 & 0 & 2 & 4 & 1 & 7 & \\
\hline & 10st-gratuate & $0.0 \%$ & $0.0 \%$ & $0.0 \%$ & $28.6 \%$ & $57.1 \%$ & $14.3 \%$ & $100.0 \%$ & \\
\hline & Totel & 1 & 14 & 8 & 39 & 52 & 11 & 125 & \\
\hline & & $0.8 \%$ & $11.2 \%$ & $6.4 \%$ & $31.2 \%$ & $41.6 \%$ & $8.8 \%$ & $100.0 \%$ & \\
\hline
\end{tabular}

PSC = Primary school certificate; JSC = Junior school certificate; SSC = Secondary school certificate; HSC = Higher Secondary certificate. 
Table 6. Social class and taking of iron tablets.

\begin{tabular}{|c|c|c|c|c|c|}
\hline \multirow{2}{*}{\multicolumn{2}{|c|}{$\begin{array}{c}\text { Monthly income } \\
\text { of the respondents family }\end{array}$}} & \multicolumn{2}{|c|}{ Taking of iron tablets } & \multirow{2}{*}{ Total } & \multirow{2}{*}{ P-value } \\
\hline & & Yes & No & & \\
\hline \multirow{10}{*}{$\begin{array}{l}\text { Monthly } \\
\text { income of the } \\
\text { respondents } \\
\text { family }\end{array}$} & \multirow{2}{*}{$<10,000$ (Taka) } & 14 & 14 & 28 & \multirow{10}{*}{0.198} \\
\hline & & $50.0 \%$ & $50.0 \%$ & $100.0 \%$ & \\
\hline & \multirow{2}{*}{$10,000-20,000$ (Taka) } & 44 & 24 & 68 & \\
\hline & & $64.7 \%$ & $35.3 \%$ & $100.0 \%$ & \\
\hline & \multirow{2}{*}{ 20,001 - 30,000 (Taka) } & 12 & 5 & 17 & \\
\hline & & $70.6 \%$ & $29.4 \%$ & $100.0 \%$ & \\
\hline & \multirow{2}{*}{$>30,000$ (Taka) } & 10 & 2 & 12 & \\
\hline & & $83.3 \%$ & $16.7 \%$ & $100.0 \%$ & \\
\hline & \multirow{2}{*}{ Total } & 80 & 45 & 125 & \\
\hline & & $64.0 \%$ & $36.0 \%$ & $100.0 \%$ & \\
\hline \multirow{12}{*}{$\begin{array}{l}\text { Occupation of } \\
\text { husband }\end{array}$} & \multirow{2}{*}{ Agriculture } & 1 & 2 & 3 & \multirow{12}{*}{0.026} \\
\hline & & $33.3 \%$ & $66.7 \%$ & $100.0 \%$ & \\
\hline & \multirow{2}{*}{ Business } & 32 & 12 & 44 & \\
\hline & & $72.7 \%$ & $27.3 \%$ & $100.0 \%$ & \\
\hline & \multirow{2}{*}{ Services } & 22 & 9 & 31 & \\
\hline & & $71.0 \%$ & $29.0 \%$ & $100.0 \%$ & \\
\hline & \multirow{2}{*}{ Day labor } & 20 & 22 & 42 & \\
\hline & & $47.6 \%$ & $52.4 \%$ & $100.0 \%$ & \\
\hline & \multirow{2}{*}{ Others } & 5 & 0 & 5 & \\
\hline & & $100.0 \%$ & $0.0 \%$ & $100.0 \%$ & \\
\hline & \multirow{2}{*}{ Total } & 80 & 45 & 125 & \\
\hline & & $64.0 \%$ & $36.0 \%$ & $100.0 \%$ & \\
\hline \multirow{16}{*}{$\begin{array}{l}\text { Educational } \\
\text { qualification }\end{array}$} & \multirow{2}{*}{ Illiterate } & 0 & 2 & 2 & \multirow{16}{*}{0.029} \\
\hline & & $0.0 \%$ & $100.0 \%$ & $100.0 \%$ & \\
\hline & \multirow{2}{*}{ PSC } & 10 & 11 & 21 & \\
\hline & & $47.6 \%$ & $52.4 \%$ & $100.0 \%$ & \\
\hline & \multirow{2}{*}{ JSC } & 6 & 8 & 14 & \\
\hline & & $42.9 \%$ & $57.1 \%$ & $100.0 \%$ & \\
\hline & & 40 & 12 & 52 & \\
\hline & & $76.9 \%$ & $23.1 \%$ & $100.0 \%$ & \\
\hline & \multirow{2}{*}{ HSC } & 12 & 8 & 20 & \\
\hline & & $60.0 \%$ & $40.0 \%$ & $100.0 \%$ & \\
\hline & \multirow{2}{*}{ Graduate } & 6 & 3 & 9 & \\
\hline & & $66.7 \%$ & $33.3 \%$ & $100.0 \%$ & \\
\hline & & 6 & 1 & 7 & \\
\hline & Post-graduate & $85.7 \%$ & $14.3 \%$ & $100.0 \%$ & \\
\hline & Total & 80 & 45 & 125 & \\
\hline & toras & $64.0 \%$ & $36.0 \%$ & $100.0 \%$ & \\
\hline
\end{tabular}


Table 7. Social class and vaccination of mother (TT).

\begin{tabular}{|c|c|c|c|c|c|}
\hline & & Vaccinat & ther (TT) & Total $>$ & P-nolue \\
\hline & & Yes & No & 10tar & T-value \\
\hline & 10000 (Talro) & 22 & 6 & 28 & \\
\hline & $<10,000(1 \mathrm{aka})$ & $78.6 \%$ & $21.4 \%$ & $100.0 \%$ & \\
\hline & & 50 & 18 & 68 & \\
\hline Monthly & $10,000-20,000$ (1 laka) & $73.5 \%$ & $26.5 \%$ & $100.0 \%$ & \\
\hline $\begin{array}{l}\text { Monthly } \\
\text { income of the }\end{array}$ & & 9 & 8 & 17 & \\
\hline respondents & $20,001-30,000$ (Taka) & $52.9 \%$ & $47.1 \%$ & $100.0 \%$ & 0.283 \\
\hline Tamily & & 8 & 4 & 12 & \\
\hline & (I aka) & $66.7 \%$ & $33.3 \%$ & $100.0 \%$ & \\
\hline & $T$ & 89 & 36 & 125 & \\
\hline & 10tar & $71.2 \%$ & $28.8 \%$ & $100.0 \%$ & \\
\hline & & 3 & 0 & 3 & \\
\hline & Agriculture & $100.0 \%$ & $0.0 \%$ & $100.0 \%$ & \\
\hline & & 29 & 15 & 44 & \\
\hline & Business & $65.9 \%$ & $34.1 \%$ & $100.0 \%$ & \\
\hline & Services & 21 & 10 & 31 & \\
\hline Occupation of & & $67.7 \%$ & $32.3 \%$ & $100.0 \%$ & \\
\hline husband & & 34 & 8 & 42 & \\
\hline & Day lavor & $81.0 \%$ & $19.0 \%$ & $100.0 \%$ & \\
\hline & & 2 & 3 & 5 & \\
\hline & Uners & $40.0 \%$ & $60.0 \%$ & $100.0 \%$ & \\
\hline & & 89 & 36 & 125 & \\
\hline & & $71.2 \%$ & $28.8 \%$ & $100.0 \%$ & \\
\hline & Illitant & 2 & 0 & 2 & \\
\hline & Hituciate & $100.0 \%$ & $0.0 \%$ & $100.0 \%$ & \\
\hline & $\mathrm{DCC}$ & 20 & 1 & 21 & \\
\hline & 10 & $95.2 \%$ & $4.8 \%$ & $100.0 \%$ & \\
\hline & $I C C_{-}$ & 11 & 3 & 14 & \\
\hline & (2) & $78.6 \%$ & $21.4 \%$ & $100.0 \%$ & \\
\hline & $\csc$ & 28 & 24 & 52 & \\
\hline Educational & & $53.8 \%$ & $46.2 \%$ & $100.0 \%$ & 0004 \\
\hline qualification & & 18 & 2 & 20 & \\
\hline & & $90.0 \%$ & $10.0 \%$ & $100.0 \%$ & \\
\hline & $C_{1} \mathrm{~d}$ & 6 & 3 & 9 & \\
\hline & Graduate & $66.7 \%$ & $33.3 \%$ & $100.0 \%$ & \\
\hline & Dor o d ott & 4 & 3 & 7 & \\
\hline & Post-graduate & $57.1 \%$ & $42.9 \%$ & $100.0 \%$ & \\
\hline & $\mathrm{T}$ & 89 & 36 & 125 & \\
\hline & & $71.2 \%$ & $28.8 \%$ & $100.0 \%$ & \\
\hline
\end{tabular}


Table 8. Social class and types of birth attendant.

\begin{tabular}{|c|c|c|c|c|c|}
\hline & & Types of $b$ & attendant & & \\
\hline & & TBA & SBA & 10lat & T-variuc \\
\hline & 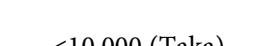 & 4 & 24 & 28 & \\
\hline & $210,000(1 \mathrm{dKd})$ & $14.3 \%$ & $85.7 \%$ & $100.0 \%$ & \\
\hline & & 3 & 65 & 68 & \\
\hline & 10,000 - 20,000 (Taka) & $4.4 \%$ & $95.6 \%$ & $100.0 \%$ & \\
\hline Monthly income & & 1 & 16 & 17 & $0 \Omega 10$ \\
\hline $\begin{array}{l}\text { of the respondents } \\
\text { family }\end{array}$ & $20,001-30,000$ ( laka) & $5.9 \%$ & $94.1 \%$ & $100.0 \%$ & 0.242 \\
\hline & $>30000$ (Tok) & 0 & 12 & 12 & \\
\hline & $200,000($ tana) & $0.0 \%$ & $100.0 \%$ & $100.0 \%$ & \\
\hline & Total & 8 & 117 & 125 & \\
\hline & & $6.4 \%$ & $93.6 \%$ & $100.0 \%$ & \\
\hline & & 0 & 3 & 3 & \\
\hline & Agricuiture & $0.0 \%$ & $100.0 \%$ & $100.0 \%$ & \\
\hline & & 3 & 41 & 44 & \\
\hline & & $6.8 \%$ & $93.2 \%$ & $100.0 \%$ & \\
\hline & Contion & 2 & 29 & 31 & \\
\hline & 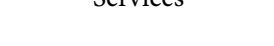 & $6.5 \%$ & $93.5 \%$ & $100.0 \%$ & \\
\hline & & 2 & 40 & 42 & \\
\hline & Day lavor & $4.8 \%$ & $95.2 \%$ & $100.0 \%$ & \\
\hline & Athore & 1 & 4 & 5 & \\
\hline & 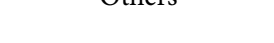 & $20.0 \%$ & $80.0 \%$ & $100.0 \%$ & \\
\hline & & 8 & 117 & 125 & \\
\hline & 10lat & $6.4 \%$ & $93.6 \%$ & $100.0 \%$ & \\
\hline & Illiterate & 1 & 1 & 2 & \\
\hline & & $50.0 \%$ & $50.0 \%$ & $100.0 \%$ & \\
\hline & $\mathrm{DSC}$ & 1 & 20 & 21 & \\
\hline & & $4.8 \%$ & $95.2 \%$ & $100.0 \%$ & \\
\hline & $J C C_{-}$ & 1 & 13 & 14 & \\
\hline & & $7.1 \%$ & $92.9 \%$ & $100.0 \%$ & \\
\hline & $\csc$ & 2 & 50 & 52 & \\
\hline Educational & & $3.8 \%$ & $96.2 \%$ & $100.0 \%$ & 0.102 \\
\hline qualification & & 3 & 17 & 20 & 0.102 \\
\hline & He & $15.0 \%$ & $85.0 \%$ & $100.0 \%$ & \\
\hline & $C=\mathrm{d}$ & 0 & 9 & 9 & \\
\hline & Gianuale & $0.0 \%$ & $100.0 \%$ & $100.0 \%$ & \\
\hline & & 0 & 7 & 7 & \\
\hline & Post-grauduate & $0.0 \%$ & $100.0 \%$ & $100.0 \%$ & \\
\hline & & 8 & 117 & 125 & \\
\hline & & $6.4 \%$ & $93.6 \%$ & $100.0 \%$ & \\
\hline
\end{tabular}


Table 9. Social class and sources of information regarding obstetric health.

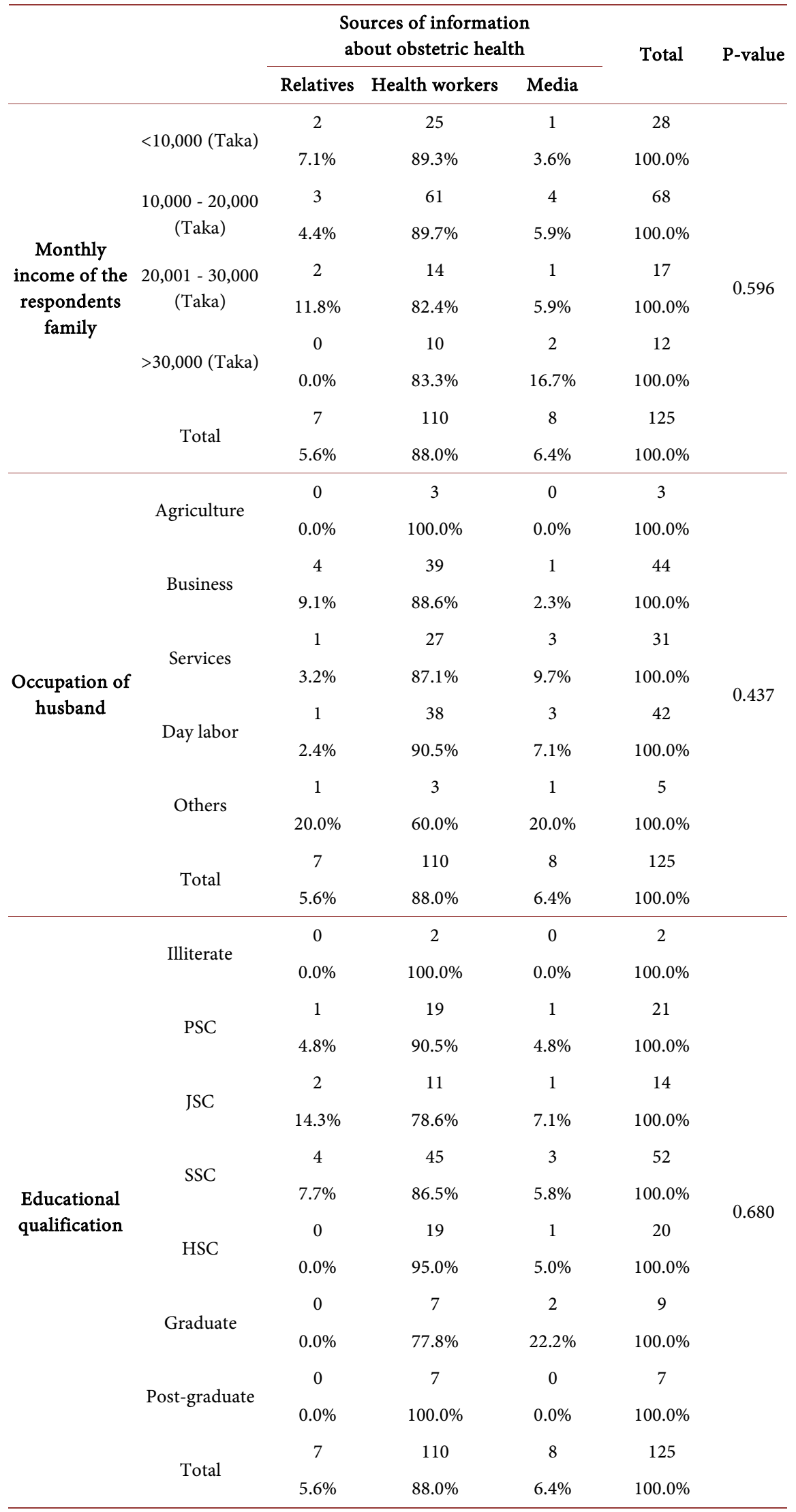


variables has been found insignificant. People from all social classes have taken information from health workers.

\section{Discussion}

The research result has shown that the performance of obstetric health behavior of the respondents is better than that of the whole country. The rate of taking ANC visit by a skilled health professional of the respondents is $99.2 \%$, whereas the rate of receiving ANC visit of the country women (at least one visit) by a skilled health professional is $63.9 \%$ (in 2014, WB, 2016). In addition to this, the rate of receiving the assistance of skilled health personnel during delivery of the respondents is $93.6 \%$, whereas the rate of the whole country is $42.1 \%$ (Bangladesh Ministry of Health and Family Welfare, 2017) [19].

It has been found that the taking of ANC visits, type of birth attendant and source of obstetric health-related information are independent of the influence of social class. In addition, the association between the monthly family income of the respondent family and the intake of iron tablets has been found insignificant. Besides, the study also shows that there is no significant relationship between vaccination of mother (TT) and the occupation of husband and monthly family income of the respondents. The findings are not similar to the Health Care Utilization Model by Anderson which has been taken as a guided theory for the present study. According to the model, one would seek care earlier than others because of different determinants which include education, occupation and monthly family income [21]. But the present study has found a different picture.

On the other hand, the research has shown that there is a significant association between the occupation of the husband of the respondents, educational qualification of the respondents and the intake of iron tablets. Besides, a significant association has also been found between vaccination of mother (TT) and educational qualification. This situation finds similarity with the Health Care Utilization Model by Anderson [21].

So it is evidenced that nowadays the effect of social class on obstetric health behavior has significantly faded. It is also evidenced that there have been some factors working behind such a situation. Mainly the availability of health services, equality-based services, and services provided through satellite clinic and the loan services of different NGOs in the research area have played a vital role in this regard, which is also observed by Anderson in his Health Care Utilization Model. It is known from the field survey that there are two medical centers named Urban Primary Health Care Services Delivery Project (UPHCSDP) operated by Rajshahi City Corporation and BRAC health center operated by BRAC NGO in the study area. The health workers from these two health centers provide ANC visits through satellite clinic every week. They follow some specific strategies. For instance, at first, they divide the area into many parts as follow the name of ghetto or colony. Then they call campaigning through satellite clinic once a week and provide ANC, TT vaccination and different information regarding obstetric health to 
the respondents. They treat all women in the same way. Due to the availability of this kind of equality based service, women from all classes can receive ANC visit without any barrier. In addition to this, being a suburban place, the study area has benefited from different governmental initiatives and the initiatives of NGOs. The respondents are being capable to overcome any obstetric complications with the assistance of these initiatives. So we can say that the geographical location of the area is very convenient which is also observed by Anderson in his Health Care Utilization Model. The place is also near to the district government medical college hospital. Moreover, there are many private clinics near the study area. In addition, the Urban Primary Health Care Services Delivery Project (UPHCSDP) provides free delivery service through "red card" which has a great impact on getting assistance from skilled health personnel during delivery. A health officer from UPHCSDP said that UPHCSDP provides two kinds of delivery services, free and paid. They carry out the survey and provide a "red card" through which women receive the assistance of skilled health personnel during delivery without any cost. On the other hand in paid service, the Bangladesh government fixed a rate of delivery charge for UPHCSDP. If the delivery is normal, it takes only BDT (Currency symbol for the Bangladesh taka) 900 and if the delivery is made through Cesar, it takes only BDT 9000. It is also known that the government also provides some allowance for pregnant women in the study area. Many of the respondents say that those who get the money could not use it the proper way. Besides, it should make clear that how Non-government Organization (NGO) influence to perform obstetric health behavior. It is also known through this study that many families take loans to maintain obstetric complications, especially during the delivery period, from NGO.

The research result does not support the Marxist Theory of Social Class which has been taken as a guided theory in this study. According to the theory, the concept of health varies according to a social group [23]. Since wealth or socio-economic factor determines the health status of both the individual and society it becomes obvious that the poor health of women is as a result of the poor economic condition. But the research result shows a different picture. People of all class perform obstetric health behavior very smoothly with a little bit of deviance.

\section{Conclusion}

The research shows that the rate of performing mentioned obstetric health behavior among the respondents in the study areas is better than the whole country because of availability of health services, equality-based health services and services through satellite clinic. Besides, the influence of social class is significantly faded by these factors. Since the receiving of ANC visits, types of birth attendant and sources of information regarding obstetric health behavior is completely independent of the influence of social class as a result of availability and equality of health service and service through satellite clinics in the study area, so 
the government of Bangladesh should take initiatives to make ANC service, skilled birth attendant and information regarding obstetric health available, accessible and affordable throughout the country to acquire the goal-3 of SDG. As the intake of iron tablets are influenced by the occupation of husband and educational qualification of the respondents, especially education has a significant influence in this regard which is associated with consciousness. So the government should take initiatives to increase health education to improve consciousness about obstetric health behavior. Besides, the government should increase allowance and ensure the proper utilization of the allowance in this regard. The government should increase health education to improve consciousness about the delivery with skilled health personnel in this regard to minimizing maternal and child death. In addition to this, we observed that respondents are capable to overcome any obstetric complications easily with the assistance of different NGOs and development projects working in the study areas. So the international communities should increase the funds in this regard throughout the world. In this way, the world community, as well as the government of Bangladesh, will able to achieve the health-related Sustainable Development Goal (SDG).

\section{Limitations of the Research}

Though I have taken all possible attempts and necessary steps to make this study fruitful, like any other sociological study, the present study has some inadequacies and limitations. The inadequacies and limitations of the present study are as follow:

First of all, in third world countries, general experiences show that it is very difficult for researchers to collect data from women respondent's, especially for male researchers. As the present study is related to maternal health so it is more difficult than any other research. That's why the researcher was unable to collect primary data with comprehension of every dialect, gesture, posture and environmental attributes. Secondly, the research result only represents the study area because of small sample size (difficulties in generalization). Thirdly, a lack of resources is also one of the important limitations. Fourthly, I have found inimical behavior of public officials in regards to providing data.

\section{Acknowledgements}

We wish to thank all the respondents of this study for giving their valuable time and answering all the questions with patience.

\section{Conflicts of Interest}

The authors declare no conflicts of interest regarding the publication of this paper.

\section{References}

[1] Park, K. (2009) Preventive and Social Medicine. BanarsidasBhanot, Jabalpur. 
[2] World Health Organization (1946) Constitution of the World Health Organization as Adopted by the International Health Conference, New York, 19-22 June 1946.

[3] Global Health Council (2000) The Importance of Womens Health. In: C.S, Atama, Ed., Socio-Cultural Factors Affecting Maternal Health: A Study of Owukpa Community, Ogbadigbo L.G.A, Benue State And Obolloeke Community, Udenu L.G.A, Enugu State.

http://www.unn.edu.ng/publications/files/images/mummy\%20final\%20\%20\%20\%2 0\%20work.pdf

[4] World Health Organization (2009) Monitoring Emergency Obstetric Care a Handbook. WHO Press, World Health Organization, Geneva.

[5] Mathe, M. (2017) Socio-Demographic Factors Affecting Utilization of Antenatal Care Services in Botswana. International Journal of Academic Research in Business and Social Sciences, 7, 477-520. https://doi.org/10.6007/IJARBSS/v7-i9/3343

[6] Lowe, M., Chen, D.R. and Huang, S.L. (2016) Social and Cultural Factors Affecting Maternal Health in Rural Gambia: An Exploratory Qualitative Study. PLoS ONE, 11, e0163653. https://doi.org/10.1371/journal.pone.0163653

[7] Ogundairo, J.A. and Jegede, A.S. (2016) Socio-Cultural Challenges in Accessing Antenatal Care by Pregnant Fulani Women in Ibarapa Central Local Government, Oyo-State, Nigeria. Annals of Public Health and Research, 3, 1043-1044.

[8] Shole, R.N. (2015) An Impact of Socio-Cultural Practices on Maternal Mortality in Masasi District, Tanzania. Malaysian Journal of Medical and Biological Research, 2 , 211-220.

[9] Dahal, R.K. (2013) Utilization of Antenatal Care Services in Rural Area of Nepal. International Journal of Collaborative Research on Internal Medicine \& Public Health, 5, 120.

[10] Asundep, N.N., April, P., Carson, C.A.T., Berhanu, T., Ada, T., Agidi, K.Z. and Pauline, E.J. (2013) Determinants of Access to Antenatal Care and Birth Outcomes in Kumasi, Ghana. Journal of Epidemiology and Global Health, 3, 279-288. https://doi.org/10.1016/j.jegh.2013.09.004

[11] Emily, C.E. (2013) A Review of Cultural Influence on Maternal Mortality in the Developing World. Midwifery, 29, 490-496. https://doi.org/10.1016/j.midw.2012.04.002

[12] Khanum, S.M. and Taufikuzzaman, M. (2012) Constraints on Women's Access to Emergency Obstetric Care in Bangladesh. University Grants Commission, Dhaka.

[13] Zakar, R., Zakar, M. and Itani, T. (2011) Factors Associated with Use of Maternal Health Care Services in Pakistan: Evidence from DHS Pakistan. Social Science \& Medicine, 68, 1349-1356. https://doi.org/10.1055/s-0031-1283690

[14] Ye, Y., Yoshitoku, Y., Rashid, H.O. and Junichi, S. (2010) Factors Affecting the Utilization of Antenatal Care Services among Women in Kham District, Xiengkhouang Province, Lao PDR. Nagoya Journal of Medical Science, 72, 23-33.

[15] Stella, B. and Adesegun, F. (2009) Determinants of Use of Maternal Health Services in Nigeria-Looking beyond Individual and Household Factors. BMC Pregnancy and Childbirth, 9, Article No. 43. http://www.biomedcentral.com/1471-2393/9/43 https://doi.org/10.1186/1471-2393-9-43

[16] Simkhada, B., Teijlingen, E.R., Porter, M. and Simkhada, P. (2008) Factors Affecting the Utilization of Antennal Care in Developing Countries: A Systematic Review of the Literature. Journal of Advanced Nursing, 61, 244-260. https://doi.org/10.1111/j.1365-2648.2007.04532.x

[17] World Health Organization Fact Sheets (2016) Maternal Mortality. 
https://www.who.int/en/news-room/fact-sheets/detail/maternal-mortality

[18] Islam, R., Rahman, M., Sadhya, G., Ahmed, N.U., Biswas, S.K., Hossain, F.A. and Sanjowal, L. (2010) Status and Utilization of Maternal Health Care Services in a Selected Rural Area of Bangladesh. Faridpur Medical College Journal, 5, 17-20. https://doi.org/10.3329/fmcj.v5i1.6808

[19] Bangladesh Ministry of Health and Family Welfare (2017) Health Bulletin 2017. Government of the People's Republic of Bangladesh Ministry of Health and Family Welfare, Dhaka.

[20] World Health Organization (2019) Maternal Health. http://www.wpro.who.int/cambodia/topics/maternal_health/en

[21] Andersen, R.M. (1995) Revisiting the Behavioral Model and Access to Medical Care: Does It Matter? Journal of Health and Social Behavior, 36, 1-10. https://doi.org/10.2307/2137284

[22] UBC Wiki (2015) Health Seeking Behavior. http://wiki.ubc.ca/Health_Seeking_Behaviour

[23] Haralambos, M., Holdborn, M. and Heald, R. (2004) Sociology: Themes and Perspectives. 6th Edition, Haper Collins Publisher, London. 